\title{
CONCEPÇÕES E PRÁTICAS SÓCIO-EDUCATIVAS PROMOTORAS DE AUTONOMIA NO ENSINO FUNDAMENTAL
}

\author{
Roselaine Vieira Sônego \\ Maria Aparecida Trevisan Zamberlan"
}

\begin{abstract}
RESUMO. A pesquisa investigou relações entre práticas sócio-educativas e desenvolvimento da autonomia, avaliando níveis de entendimento inter-pessoal segundo Selman. A coleta de dados conduzida em duas escolas, uma particular e outra pública, utilizou observação naturalística e um questionário semi-estruturado, aplicados a docentes e a alunos de ensino fundamental. Na escola particular os resultados indicam: maior homogeneidade de níveis no entendimento inter-pessoal dos alunos, relacionados a concepções e às práticas sócio-educativas dos docentes e maior equilíbrio entre as estratégias de negociação e experiências inter-pessoais compartilhadas. Na escola pública houve maior colaboração entre as crianças. Nas duas escolas, a concepção docente sobre suas práticas foi positiva com atribuição elevada ao ensino de valores morais, porém com justificativas ainda unilaterais. Níveis superiores de adoção de perspectiva social correlacionaram-se inversamente com a frequiência de pronunciamentos coercitivos e heterônomos. Os dados confirmam a importância do desenvolvimento da autonomia discente na escola condicionada a intervenções de professores.
\end{abstract}

Palavras-chave: práticas sócio-educativas, perspectiva social, autonomia.

\section{CONCEPTIONS AND SOCIAL EDUCATION PRACTICES PROMOTED AUTONOMY IN PRIMARY EDUCATION}

\begin{abstract}
The research investigated the relations between practices partner and the development of autonomy, evaluating dynamic of interpersonal agreement, by Selman. The colecta data instruments were the naturalistic study and a half questionnaire structuralized, composed of 7 categories, for application to teachers, and 4 categories, for pupils applied in the field on a private and a public schools. The data, pointing in the school A: to a more homogeneous relation between the your practice and educative procedures partner with the perceptions and levels of interpersonal agreement of the pupils; one high importance for the education of moral values, but its justifications had tends the unilateralism; bigger balance enter the shared strategies of negotiation and experiences in interpersonal dynamic in the school A; a bigger sense of cooperation enter the children of school B; in both the schools the superior levels of perspective adoption had evidenced minor frequency of coercive and heteronomic uprisings. The data show it's necessary interventions of the teachers, guided for the autonomic development of children in basic education.
\end{abstract}

Key words: Social and educational practices, social perspective, autonomy.

\section{CONCEPCIONES Y PRÁCTICAS SOCIOEDUCATIVAS PROMOTORAS DE AUTONOMÍA EN LA EDUCACIÓN PRIMARIA}

\begin{abstract}
RESUMEN. El trabajo investigó relaciones entre prácticas socioeducativas y desarrollo de la autonomía, evaluando niveles de entendimiento interpersonal según Selman. La colecta de datos, conducida en dos escuelas - una privada y una pública - utilizó observación naturalística y un cuestionario semiestructurado, aplicados a docentes y alumnos de la educación primaria fundamental. En la escuela privada los resultados indican: mayor homogeneidad de niveles en el entendimiento interpersonal de los alumnos relacionados a concepciones y a las prácticas socioeducativas de los docentes y mayor equilibrio entre las estrategias de negociación y experiencias interpersonales compartidas. En la escuela pública hubo mayor colaboración entre los niños. En las dos escuelas, la concepción docente sobre sus prácticas fue positiva, con asignación elevada a la enseñanza de valores morales, pero con justificativas todavía unilaterales. Niveles superiores de adopción de perspectiva se correlacionaron inversamente con la frecuencia de pronunciamientos coercitivos y heterónomos. Los datos confirman la importancia del desarrollo de la autonomía discente en la escuela condicionada a intervenciones de profesores.
\end{abstract}

Palabras-clave: prácticas socioeducativas, perspectiva social; autonomía.

* Mestre em Educação pela Universidade Estadual de Londrina.

\# Doutora. Professora do Programa de Pós-graduação em Educação da Universidade Estadual de Londrina. 


\section{A PERSPECTIVA DE ENTENDIMENTO INTERPESSOAL DE SELMAN}

Um pesquisador não muito destacado no Brasil, mas que contribui muito para os estudos sobre moral no contexto escolar é Selman. Seu trabalho trata de um estudo longitudinal, com base em Piaget e Kohlberg, em que considera essencial a adoção da perspectiva do outro na assunção de papéis, no desenvolvimento do pensamento moral. Em outras palavras, o autor hipotetiza uma correlação entre cognição, moralidade e aspectos interpessoais.
A contribuição desses teóricos precursores da teoria moral permite o entendimento das bases teóricas e da continuidade de pesquisa voltada para investigações que considerem a prática, a aplicabilidade de seus pressupostos, buscando formar a crescente autonomia de todos os envolvidos nesse processo.

No Quadro 1 nos apoiamos nas idéias dos autores citados que demonstram essa relação e fazemos alusão aos trabalhos de Selman que discutiu os níveis centrais de desenvolvimento na coordenação da perspectiva social.

Quadro 1. Relação entre os Estágios de Desenvolvimento Cognitivo de Piaget, Estágios de Desenvolvimento Moral de Kohlberg e Níveis de Entendimento Interpessoal de Selman

\begin{tabular}{|c|c|c|c|}
\hline Estágios cognitivos & Estágios morais & \multicolumn{2}{|c|}{$\begin{array}{l}\text { Níveis centrais de desenvolvimento } \\
\text { na coordenação da perspectiva social }\end{array}$} \\
\hline \multirow[b]{2}{*}{ Pré-Operacional: 2-7 anos } & \multirow[b]{2}{*}{ Estágio 1 (Heteronomia): } & Estratégias de negociação & Experiências compartilhadas \\
\hline & & \multicolumn{2}{|c|}{ Nível Impulsivo Egocêntrico(0): 0-4 anos } \\
\hline $\begin{array}{l}\text { A função simbólica aparece, mas o } \\
\text { pensamento é marcado pela centração e } \\
\text { irreversibilidade. }\end{array}$ & $\begin{array}{l}\text { O certo e o errado são determinados } \\
\text { pela autoridade e pela conseqüência } \\
\text { física das ações. }\end{array}$ & $\begin{array}{l}\text { Negociação através de estratégias } \\
\text { físicas irreflexivas (luta ou fuga } \\
\text { impulsiva). }\end{array}$ & $\begin{array}{l}\text { Experiência compartilhada } \\
\text { através da imitação irreflexiva } \\
\text { (contagiante). }\end{array}$ \\
\hline Operações Concretas: 7-11 anos & Estágio 2 (Trocas): & \multicolumn{2}{|c|}{ Nível Unilateral (1) 5-9 anos } \\
\hline $\begin{array}{l}\text { Surge a classificação, conservação, } \\
\text { seriação e o objetivo é diferenciado do } \\
\text { subjetivo. }\end{array}$ & $\begin{array}{l}\text { A interação cooperativa é baseada em } \\
\text { simples trocas, e o certo é definido } \\
\text { como o que serve aos próprios } \\
\text { interesses e desejos. }\end{array}$ & $\begin{array}{l}\text { Negociação através de comandos / } \\
\text { ordens unilaterais em uma só direção } \\
\text { ou por meio de estratégia de obediência } \\
\text { automática. }\end{array}$ & $\begin{array}{l}\text { Experiência compartilhada } \\
\text { através de entusiasmo sem } \\
\text { preocupação com a } \\
\text { reciprocidade. }\end{array}$ \\
\hline $\begin{array}{l}\text { Início das Operações Formais:11-12 } \\
\text { anos }\end{array}$ & Estágio 3 (Expectativas): & \multicolumn{2}{|c|}{ Nível Reflexivo Recíproco (2): 7 -12 anos } \\
\hline $\begin{array}{l}\text { Há o desenvolvimento da coordenação } \\
\text { de reciprocidade com inversão e } \\
\text { aparece a lógica proposicional. }\end{array}$ & $\begin{array}{l}\text { A ênfase é dada para o estereótipo do } \\
\text { bom sujeito e age buscando a } \\
\text { aprovação dos outros. }\end{array}$ & $\begin{array}{l}\text { Negociação através de estratégias } \\
\text { cooperativas em uma orientação } \\
\text { persuasiva ou diferenciada. }\end{array}$ & $\begin{array}{l}\text { Experiência compartilhada através } \\
\text { da reflexão conjunta sobre } \\
\text { percepções ou experiências } \\
\text { semelhantes. }\end{array}$ \\
\hline Operações Formais Básicas: & Estágio 4 (Sistema Social): & \multicolumn{2}{|c|}{ Nível Mútuo de Terceira Pessoa (3) Adolescente } \\
\hline $\begin{array}{l}\text { Surge o raciocínio hipotético-dedutivo, } \\
\text { envolvendo habilidades para estabelecer } \\
\text { relações entre variáveis e organizar } \\
\text { análises experimentais. }\end{array}$ & $\begin{array}{l}\text { Busca a manutenção da ordem social } \\
\text { por meio da obediência às leis e busca } \\
\text { cumprir suas obrigações. }\end{array}$ & $\begin{array}{l}\text { Negociação através de estratégias } \\
\text { cooperativas orientadas para } \\
\text { integração as necessidades de si } \\
\text { mesmo e de outros. }\end{array}$ & $\begin{array}{l}\text { Experiência compartilhada através } \\
\text { de processos reflexivos, empáticos e } \\
\text { cooperativos. }\end{array}$ \\
\hline Operações Formais Consolidadas: & Estágio 5 (Contrato Social): & \multicolumn{2}{|c|}{$\begin{array}{l}\text { Nível de Terceira Pessoa(s) num núcleo integrativo: Final da } \\
\text { adolescência ou idade adulta }\end{array}$} \\
\hline $\begin{array}{l}\text { As operações tornam-se completamente } \\
\text { exaustivas e sistemáticas. }\end{array}$ & $\begin{array}{l}\text { O certo é definido pelos acordos } \\
\text { mútuos estabelecidos por toda a } \\
\text { sociedade. }\end{array}$ & $\mid \begin{array}{llll}\text { Negociação } & \text { através de estratégias } \\
\text { cooperativas } & \text { pela tentativa mútua de } & & \text { E } \\
\text { introspecção } & \text { e } & \text { auto-reflexão, } \\
\text { admitindo } & \text { a } & \text { ambivalência de } & \text { de } \\
\text { emoções. } & & & \text { a } \\
& & & \text { d } \\
& & \\
& \end{array}$ & $\begin{array}{l}\text { Experiência compartilhada através } \\
\text { relações de natureza coesiva, } \\
\text { pluralística em conceito, orientadas } \\
\text { ao compromisso de alcançar } \\
\text { determinados objetivos. Admitindo } \\
\text { que o outro possa crescer fora do } \\
\text { relacionamento já existente. }\end{array}$ \\
\hline
\end{tabular}

Fonte: Adaptado de Lukjanenko (2001); Selman (1980) e Selman (citado por DeVries e Zan,1998).

Consciente da precariedade de estudos sobre moral, da complexidade contextual, da dificuldade de avaliar julgamento e comportamento moral e da carência de estudos que considerem o papel das práticas sócio-educativas, nesses processos, elegemos Selman (1980) como teórico de base nessa pesquisa.
Levantamos como hipótese de trabalho que "os procedimentos sócio-educativos podem contribuir para o desenvolvimento da autonomia no que se refere à adoção de perspectiva".

Nas salas de aulas, os ambientes em que os protagonistas agem estão compostos por díades ou tríades (professor - aluno, aluno - aluno, e, professor 
- aluno - e outro aluno), e nelas, o desenvolvimento da autonomia está relacionado ao potencial de adoção de perspectiva dos próprios papéis, dos papéis do outro e das expectativas sociais que se formam acerca dos mesmos.

Para a investigação desse problema, no que concerne ao referencial teórico e aos instrumentos metodológicos, duas questões foram geradas: Como podem ser avaliados os aspectos do desenvolvimento sócio-moral na perspectiva de autores que enfocaram o assunto e se tais instrumentos fornecem subsídios para réplica e ou adaptações em nossos contextos educacionais? Qual o papel das práticas e concepções sócio-educativas no desenvolvimento de comportamentos sócio-morais nas dinâmicas de entendimento interpessoal, vivenciadas por protagonistas escolares distintos do Ensino Fundamental?

O estudo procura contribuir sobre o assunto como subsídio ao conhecimento do universo escolar e à formação de educadores e de sua atuação em ambientes sócio-morais diferenciados.

\section{OBJETIVOS E MÉTODO}

A pesquisa consistiu em investigar, em duas salas de aula de instituições distintas, as relações entre concepções e práticas sócio-educativas e o desenvolvimento da autonomia, no que se refere às dinâmicas de entendimento interpessoal, fundamentando-se nos pressupostos teóricos de Selman (1980). Os objetivos básicos do estudo foram: $1^{\mathrm{o}}$ ) levantar dados sobre concepções e formas de atuação de educadores de duas instituições quanto a práticas promotoras de autonomia sóciomoral na educação básica; $2^{\circ}$ ) descrever e avaliar aspectos do ambiente sócio-moral gerado por suas práticas, enquanto educadores atuantes junto a crianças de 9 a 10 anos, de duas instituições; e correlacionar dados quali-quantitativos resultantes da aplicação dos dois instrumentos de coleta de informações. Foram utilizados como técnicas de coleta de dados a observação naturalística, com registros em diário de campo e um questionário semi-estruturado composto por 7 categorias, para a aplicação com os docentes e 4 categorias, para os alunos, os quais foram aplicados nas Escolas A, particular, e B, pública.

As observações, a partir do diário de campo, ao longo de sete sessões conduzidas permitiram a triagem das informações das Escolas A e B referentes a categorias e níveis de entendimento interpessoal atuados, segundo Selman (1980), que identificam a coordenação da perspectiva social ou adoção de perspectiva de professores e alunos:

- nível impulsivo egocêntrico (0);

- nível unilateral (1);

- nível reflexivo recíproco (2);

- nível mútuo de terceira pessoa (3);

- nível de terceira pessoa (s) num núcleo integrativo (4). ${ }^{1}$

Para a quantificação, foram analisados os pronunciamentos e ações, registrados no diário de campo tomando-se os seguintes procedimentos: a) diferenciou-se as estratégias de negociação das experiências compartilhadas; b) identificou-se as dinâmicas interpessoais em situações de equilíbrio e desequilíbrio; c) classificou-se ou caracterizou-se os tipos ou formas de interação verbal, físico ou comportamental (ameaças, críticas, elogios, desafios, dentre outros); d) identificou-se, em cada pronunciamento ou dinâmica em equilíbrio (pe) ou desequilíbrio (pd), o nível de coordenação ou adoção de perspectiva; e) quantificou-se a soma geral dessas interações, especificando-se o total de cada uma de suas formas e dos referidos níveis.

\section{RESULTADOS E ANÁLISES}

Os resultados obtidos nas duas escolas, permitiram uma comparação quantitativa dos níveis de adoção de perspectiva explicitados, individualmente, pelos professores (P1, P2, P3 e P4) e coletivamente pelas crianças, em cada universo escolar, dentro de cada período de observação.

Analisando os escores individuais obtidos entre os professores das duas escolas, percebeu-se que na escola A todos eles pontuaram os níveis (1 e 2) sendo o nível 1 mais elevado que o nível 2, enquanto na escola $B$, o $\mathrm{P} 2$ fez mais pronunciamentos no nível 2 e o P3 só o fez no nível 1. O mesmo ocorreu com o nível 3, pois na escola A, todos os professores atingiram esse nível com exceção do P3 que, por sua vez, teve um menor tempo de observação, enquanto na escola B, somente o P2 atingiu o nível 3, com um total de

Esse nível não foi considerado, porque, via de regra, emerge apenas ao final da adolescência ou na idade adulta, não envolvendo crianças pequenas, como confirma DeVries e Zan (1998, p. 42). 
4,7\%, mesmo não sendo o mais observado, em termos de horas.

Esses dados indicam que na escola $\mathrm{A}$, as interações dos professores com os alunos apresentaram maior semelhança quanto ao nível de adoção de perspectiva. Já na escola B os professores apresentaram diferenças acentuadas, como, por exemplo, o P1 e P2: enquanto P1 enfocou hierarquicamente os níveis 1,0 e 2, o discurso e ações do P2 foram centrados nos níveis, 2, 1 e 3.

Outro dado relevante, é que a escola A apresentou maior harmonia entre as dinâmicas interpessoais de equilíbrio e desequilíbrio em comparação com a escola B. $\mathrm{Na}$ escola A, considerando que os 193 pronunciamentos equivalem a $100 \%$, a diferença entre as dinâmicas de equilíbrio foi de $25,12 \%$, já que $62,17 \%$ referiram- se aos pronunciamentos em equilíbrio (pe) e $37,05 \%$ aos em desequilíbrio (pd). A escola $\mathrm{B}$, por sua vez, totalizou 175 pronunciamentos, entre os quais, os (pe) perfizeram 70,85 \% e os (pd) pontuaram $29,14 \%$ apresentando uma diferença de $41,71 \%$, confirmando, assim, que o corpo docente da escola B foi muito distinto em seus níveis de adoção de perspectiva quanto ao entendimento interpessoal atuados.

Além disso, a escola A também diferenciou-se da escola B quanto a flutuação entre os níveis 1 e 2 , totalizando $1,03 \%$ de flutuação regressiva do nível $1(0), 6,21 \%$ de flutuação progressiva do nível 1(2) e $4,14 \%$ de regressão no nível 2(1), ressaltando que apenas o P4 não apresentou nenhum tipo de flutuação entre esses níveis. Tais dados podem estar relacionados ao fato de que a escola A possui uma filosofia que os desafiam à uma prática educativa mais centrada em valores morais regidos por ideais religiosos, mas que, ainda carece de ações mais objetivas para criar um ambiente sócio-moral mais cooperativo e autonômico. A escola B, diferentemente, não apresentou nenhum tipo de flutuação entre os níveis, o que pode indicar que as práticas sócio-educativas de seus professores estão centradas nos seus respectivos estilos de liderança conforme estudos de Abrantes; Amado; Lopes; Jakson e Woods (citados por Amado, 2005).

Nas duas escolas os professores perderam o controle próprio, a diferença é que na escola $\mathrm{A}$ isso ocorreu duas vezes com o P1 (quando falou alto e intimidou emocionalmente a criança, dizendo que deveria limpar a carteira e quando ameaçou um aluno ao dizer que iria tirá-lo da sala), enquanto na escola B isso aconteceu 6 vezes com o P1 e, 5 vezes com o P4, que, além da intimidação emocional, gritaram com as crianças.

$\mathrm{O}$ fato da escola $\mathrm{B}$ ser pública, pode explicar a alta freqüência da perda do auto-controle por alguns professores, uma vez que há uma preocupação bem menos acentuada nas exigências dos pais, em se comparando, com a escola particular.

Os pronunciamentos dos alunos e professores, nas duas escolas, se assemelharam quanto à variação de itens (demandas, elogios, pedidos de esclarecimentos, ameaças, dentre outros). Mas há que se destacar o estilo do P4 da escola A e o P2 da escola B.

Os dados observados mostraram que o P4 (escola A) faz elogios; pede esclarecimento das idéias e comportamentos explicitados; usa o elogio como reforço positivo; utiliza estratégias persuasivas, desafios, questões teste para redirecionar o comportamento do aluno ou motivar sua participação; faz demandas, pedidos e esclarecimentos para solicitar o que deseja, e ainda, efetiva essas ações chegando ao nível 3 (25\%) de entendimento interpessoal, numa freqüência considerável, se ponderarmos que foi observado em apenas uma hora. Outro dado importante é que os $(\mathrm{pe}=75 \%)$ superaram os $(\mathrm{pd}=25 \%)$ em $50 \%$ diferenciando-se dos demais professores da escola A.

O P2 (escola B), por sua vez, apesar de quebrar a regra estabelecida por duas vezes e proferir três exigências/ordem, de igual modo, apresentou as mesmas características positivas do P4, destacandose o fato de utilizar muitos pedidos de esclarecimentos, sendo que os mesmos, foram sempre direcionados a auto-reflexão da criança quanto a seus atos e pensamentos. De todos os professores observados, o P2 da escola $\mathrm{B}$, foi $\mathrm{O}$ único a ter maior pontuação no nível 2 (47.5\%), 1 $(32.5 \%)$, destacando-se pontuação elevada no nível $3(20 \%)$. Assim como o P4 da escola A, o P2 da escola B, também, obteve maior pontuação para os $(\mathrm{pe}=60 \%)$ e menor para os $(\mathrm{pd}=40 \%)$, totalizando uma superação de $20 \%$.

Em termos de níveis de entendimento interpessoal atuados, as crianças da escola A e da escola B apresentaram maior pontuação no mesmo nível de seus professores, tendo ambas escolas o nível 1, com maior pontuação. No entanto, a diferença dos resultados dos professores e alunos, nesse nível, da escola $\mathrm{A}$ foi de $4.88 \%$ enquanto da escola B foi de $30.15 \%$, indicando que na escola B 
talvez, devido a maior diversidade de estilos de professores, como mensurado anteriormente, as práticas sócio-educativas por eles efetivadas tenham menor influência sobre o comportamento das crianças, enquanto a existência de uma certa uniformidade na escola $\mathrm{A}$, quanto aos estilos de seus professores, possa ter maior influência no desenvolvimento de estratégias e habilidades de interação entre as crianças que as aprendem.

Ainda sobre a semelhança da pontuação entre professores e alunos das duas escolas, quanto ao nível 1, significa que as práticas sócio-educativas estão relacionadas aos comportamentos dos alunos, mobilizando-os para a produtividade, agressividade, cooperação, como aponta os estudos de Araújo(1996/1999); DeVries e Zan (1998); e a pesquisa de Lewin, Lippitt e White (citado por Bronfenbrenner, 1996).

Nas duas escolas o nível 2 foi o segundo maior pontuado pelos professores, mas nas interações das crianças o nível 1 foi o segundo enfocado. Isso está relacionado à idade das crianças que, de modo geral, está centrado nos níveis 2 e 1 , tanto é que a diferença entre as crianças da escola A e B para o nível 1 foi de apenas $5.07 \%$.

A Tabela 1 compara sinteticamente cada nível, os resultados obtidos, apontando suas diferenças.

Tabela 1. Diferenças Percentuais Entre os Resultados Pontuados pelas Crianças e Professores das Escolas A e B

\begin{tabular}{l|c|c|c|c|c|c}
\hline & \multicolumn{3}{|c|}{ Escola A } & & Escola B \\
\hline $\begin{array}{l}\text { Níveis de entendimento } \\
\text { interpessoal }\end{array}$ & Professores & Alunos & Diferenças & Professores & Alunos & Diferenças \\
\hline $\mathbf{0}$ & $2.07 \%$ & $22.2 \%$ & $20.13 \%$ & $7.43 \%$ & $27.27 \%$ & $19.84 \%$ \\
\hline $\mathbf{1}$ & $62.69 \%$ & $57.8 \%$ & $4.89 \%$ & $72.57 \%$ & $42.43 \%$ & $30.32 \%$ \\
\hline $\mathbf{2}$ & $32.64 \%$ & $13.3 \%$ & $19.34 \%$ & $15.43 \%$ & $15.15 \%$ & $0.28 \%$ \\
\hline $\mathbf{3}$ & $2.6 \%$ & $6.7 \%$ & $4.1 \%$ & $4.57 \%$ & $15.15 \%$ & $10.58 \%$ \\
\hline TOTAL & $100 \%$ & $100 \%$ & $48.4 \%$ & $100 \%$ & $100 \%$ & $61.02 \%$ \\
\hline
\end{tabular}

Fonte: Dados Primários Obtidos na Escola A e B

Esses resultados demonstram que o total de diferenças de níveis atingidos entre professores e alunos foram $12.62 \%$ menores na escola $\mathrm{A}$, confirmando a questão já posta da uniformidade diversidade de estilos de lideranças estudada por Lewin e cols. (citados por Bonfenbrenner, 1996, p. 81).

Outro fator importante é que na escola A e B os alunos tiveram menor pontuação nos níveis 2 e 3 , contudo, a escola B pontuou $30.3 \%$ e a escola A $20 \%$, perfazendo uma diferença de $10,3 \%$ a mais para a escola B. Isso pode estar relacionado, ao fator idade, que na escola B é mais elevado e, também, ao contexto familiar e social dessas crianças, que por terem condições menos favoráveis de qualidade de vida, desenvolvem habilidades de resolução de conflitos mais elaboradas ou mais cooperativas. Isso foi observado com a questão de empréstimos de materiais em sala de aula, em que essas crianças demonstraram preocupação com as necessidades alheias enquanto as crianças da escola A demonstraram um sentimento de posse mais acentuado sobre seus materiais, através de condutas egoísticas. Isso evidencia o pressuposto de Bronfenbrenner (1996) de que a condição sistêmica dos ambientes em todos os contextos (do micro e macro sistema) influenciam seus protagonistas.

Considerando o pressuposto teórico de que a adoção de perspectiva elevada indica que o sujeito descentrou-se, saindo da unilateralidade para a reciprocidade; da heteronomia para autonomia, podemos relacionar o nível de controle dos professores sobre as crianças, com a pontuação de adoção de perspectivas por eles efetivadas. Logo, é possível mensurar o nível de autonomia por eles proporcionados. Os gráficos apresentados (Figura $1 \mathrm{e}$ 2) apresentam dados que ilustram esta possível relação. 


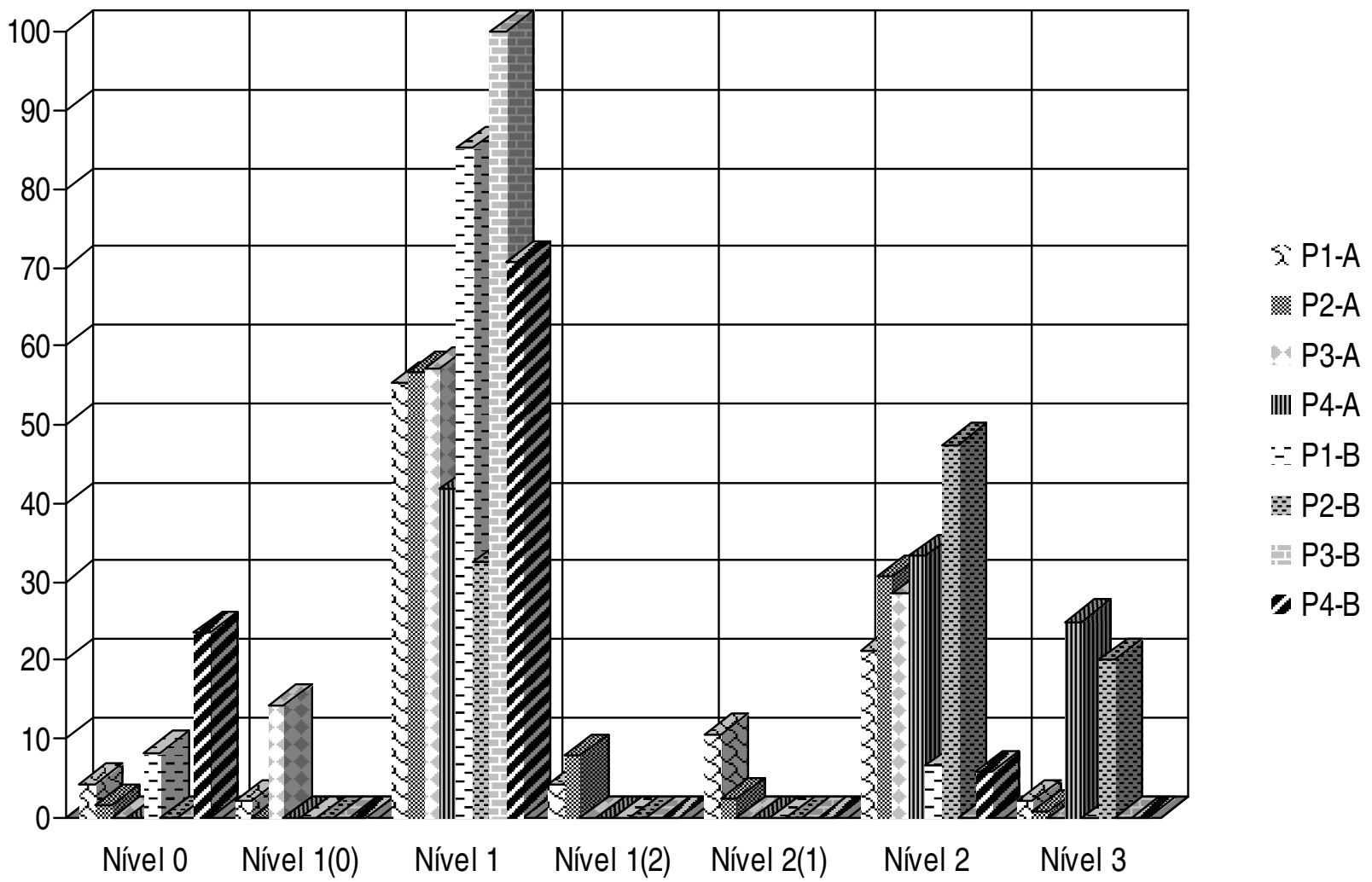

Fonte: Dados Primários Obtidos na Escola A e B

Figura 1. Comparação dos Níveis de Entendimento Interpessoal Entre os Professores das Duas Escolas

Como se constatou, o corpo docente da escola A apresentou maior harmonia quanto aos níveis de entendimento interpessoal em relação à escola $\mathrm{B}$. Constata-se que quanto mais os professores tendem a níveis superiores de adoção de perspectiva, menor é a freqüência de pronunciamentos unilaterais, coercivos, que levam à heteronomia.

Outro fato relevante é que o estilo dos professores quanto aos comportamentos ou pronunciamentos manifestos, mantiveram uma constância, caracterizando-os quanto a um perfil mais ou menos democrático ou assertivo em suas interações como descrito por Freire (citado por Amado, 2005).

Além disso, os pronunciamentos registrados possibilitaram uma caracterização das interações dos protagonistas revelando que, de modo geral, o perfil docente da escola A (4 professores observados) tende à produtividade, gerando um ambiente sócio-moral de pressão obediente, em que os alunos manifestam uma insegurança sobre sua produção e, por isso, mantêm um vínculo de dependência à figura do professor.

Já os pronunciamentos da escola $B$, não permitiram traçar um perfil geral de seus professores, por serem muito distintos, mas revelaram que como a maioria tende ao nível 1 de modo elevado, o ambiente sócio-moral pode ser caracterizado pela pressão obediente, apesar de realizarem muito mais atividades voltadas ao processo construtivo da aprendizagem, do que a escola A. Nesse ambiente, a P1 se destacou como uma sargenta-instrutora e, a P2 como uma gerente que propicia um ambiente sócio moral de respeito, cooperação e auto-regulação (DeVries e Zan, 1998, p. 31-32).

Há diferenças significativas na atuação dos professores das duas escolas, sugerindo interações também diferenciadas com seus alunos, conforme indica a figura 2 . 


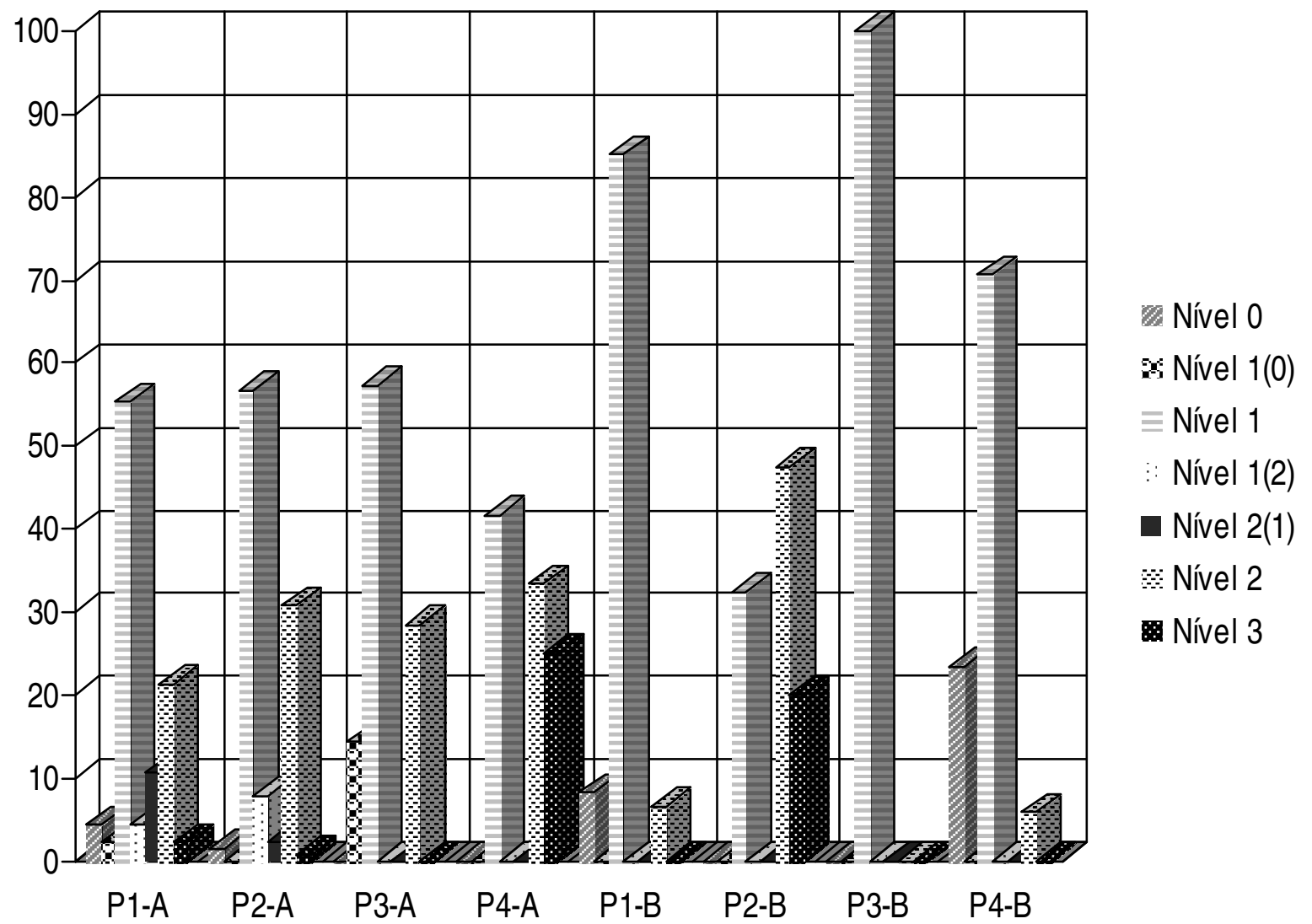

Fonte: Dados Primários Obtidos na Escola A e B

Figura 2. Comparação dos Professores das Duas Escolas Quanto aos Níveis de Entendimento Interpessoal

As sessões de observação naturalísticas nas duas escolas evidenciaram que o ambiente escolar carece de situações que favoreçam o conflito cognitivo, afetivo e social nas interações de seus protagonistas, e que, sobretudo, sejam compreendidos por seus professores e mediados numa direção crescente e freqüente de autonomia.

\section{CONSIDERAÇÕES FINAIS}

Este trabalho focaliza práticas sócio-educativas na escola como subsídio ao conhecimento do universo escolar e à formação de educadores, demonstrando como estes conduzem sua atuação em ambientes sóciomorais diferenciados. As observações, a partir do diário de campo, ao longo de sete sessões conduzidas permitiram a triagem das informações de duas escolas, uma pública e outra particular, delineando categorias e quantificando os níveis de entendimento interpessoal na relação professor-aluno e aluno-aluno, atuados segundo Selman (1980) em: nível impulsivo egocêntrico (0); nível unilateral (1); nível reflexivo recíproco (2); nível mútuo de terceira pessoa (3). Para a quantificação, foram analisados os pronunciamentos e ações, registrados no diário de campo diferenciandose as estratégias de negociação das experiências compartilhadas; as dinâmicas interpessoais em situações de equilíbrio e desequilíbrio e classificandose os tipos ou formas de interação verbal, físico ou comportamental. Para aferir o nível de coordenação ou adoção de perspectiva quantificou-se a soma geral dessas interações, pelos valores atribuídos nos referidos níveis. Os dados apontaram: a) uma relação mais homogênea entre as práticas e procedimentos sócio-educativos dos professores com as percepções e níveis de entendimento interpessoal dos alunos para a escola A; b) maior equilíbrio entre as estratégias de negociação e experiências compartilhadas em dinâmicas interpessoais na escola $\mathrm{A}$; c) um senso maior de colaboração entre as crianças da escola B, d) uma concepção docente positiva das práticas sócioeducativas e elevada importância para o ensino de 
valores morais, mas suas justificativas revelam que o conceito que possuem destes itens tende à unilateralidade. Em ambas as escolas, os níveis superiores de adoção de perspectiva evidenciaram menor freqüência de pronunciamentos coercitivos e heterônomos. Há diferenças significativas na atuação dos professores das duas escolas, sugerindo interações também diferenciadas com seus alunos. Esses achados indicam a necessidade de intervenções de professores orientadas para o desenvolvimento autonômico de alunos no ensino fundamental.

\section{REFERÊNCIAS}

Amado, J. da S. (2005). Indisciplina e violência na escola: conceitos, interrogações e respostas. Revista Teoria e Prática da Educação, 7(2), 43-52. [no prelo].
Araújo, U. F. (1999, 2 2a Ed.). O ambiente escolar e o desenvolvimento do juízo moral. Em L. de Macedo (Org.), Cinco estudos de educação moral (pp. 120-128). São Paulo: Casa do Psicólogo. (Original publicado em 1996).

Bronfenbrenner, U. (1996). A ecologia do desenvolvimento humano: experimentos naturais e planejados. Porto Alegre: Artes Médicas.

DeVries, R. \& Zan, B. (1998). A ética na educação infantil. Porto Alegre: Artemed.

Selman, R. L. (1980). The growth of interpersonal understanding. New York: Academic.

Recebido em 19/10/2005 Aceito em 08/04/2006

Endereço para correspondência: Roselaine Vieira Sônego. Rua: Emídio Alves Feitosa, 2083, Nova Porto Velho, CEP 78909_ 120, Porto Velho-RO. E-mail: rosesonego@yahoo.com.br 